\title{
Direct electrochemistry of human, bovine and porcine cytochrome P450c17
}

\author{
D L Johnson, A J Conley ${ }^{\mathbf{1}}$ and L L Martin \\ School of Chemistry, Monash University, Victoria, 3800, Australia \\ ${ }^{1}$ School of Veterinary Medicine, University of California, Davis, California, USA \\ (Requests for offprints should be addressed to L L Martin; Email: Lisa.Martin@sci.monash.edu.au)
}

\begin{abstract}
The direct electrochemistry of human, bovine and porcine cytochrome P450c17 (CYP17) has been examined on an edge-oriented pyrolytic graphite electrode. The recombinant protein was immobilized on an electrode modified with a surfactant to simulate the environment of a biological membrane, and hence physiological electron-transfer conditions. The P450 enzymes all retained 'electron-transfer' activity while immobilized at the electrode surface as assessed by the presence of catalytic signals under aerobic conditions. The redox potentials for porcine P450c17 were more positive (anodic) than both the human and bovine forms, perhaps reflecting the differences in substrate specificity for these species. In addition, these enzymes were all influenced by $\mathrm{pH}$, consistent with a single proton associated with the single electron-transfer event. lonic strength of the buffer medium also shifted the redox potentials towards positive, suggesting that electrostatic forces contribute to the protein environment required for the electron-transfer process. The effect of substrate on the redox potential for each P450c17 was measured in the presence of pregnenolone,

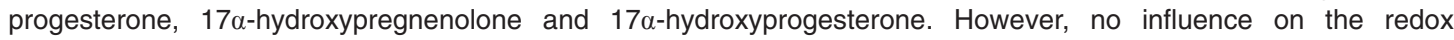
parameters was observed.
\end{abstract}

Journal of Molecular Endocrinology (2006) 36, 349-359

\section{Introduction}

The ubiquitous cytochrome P450 enzymes (P450s) are a superfamily of enzymes involved in the oxidation of a wide range of endogenous sterols, fat soluble vitamins and fatty acids, as well as a variety of xenobiotics (Estabrook 2003, Johnson et al. 2005, Omura 1999). The vast majority of reactions catalyzed by $\mathrm{P} 450 \mathrm{~s}$ involve the two-electron reduction of molecular oxygen, the energetically taxing insertion of an oxygen atom into a substrate $\mathrm{C}-\mathrm{H}$ bond, and the production of water $(\mathrm{Li}$ 2001). Much has been learned about the biochemistry of these proteins from studies on prokaryote $\mathrm{P} 450 \mathrm{~s}$, but there are fundamental differences between prokaryotic and eukaryotic P450s. Prokaryotic P450s are soluble and often self-supporting, whereas $\mathrm{P} 450$ s expressed in eukaryotes are membrane-bound, with some in the endoplasmic reticulum (microsomal forms) and others in mitochondria. Most microsomal and all mitochondrial P450s require distinct accessory proteins to transfer electrons from the donor to activate oxygen- and metabolize-bound substrates. Therefore, while undoubtedly sharing inherent similarities, essential differences exist among P450 enzymes that might be reflected in even the most fundamental mechanisms controlling substrate metabolism.
Among eukaryotic enzymes, the so-called steroidogeneic P450s generally metabolize a narrower range of substrates than other members of the superfamily. Cytochrome $\mathrm{P} 450$ s expressed in the adrenal cortex and gonads catalyse critical steps in the synthesis of adrenal corticoids and the sex steroid hormones. 17 $\alpha$ hydroxylase/17,20-lyase cytochrome P450 (P450c17), a microsomal enzyme, is particularly noteworthy among them for several reasons. P450c17 is not only essential in the production of both adrenal and gonadal steroids, it occupies a key regulating branch point in the pathway, leading to either corticoid or androgen production (Conley \& Bird 1997). Importantly, P450c17 is one of only three P450s involved in steroid synthesis that catalyzes concerted oxygenation reactions culminating in cleavage (lyase activity) of a side-chain group. Moreover, this 17,20-lyase activity is profoundly substratespecific, and variably so across mammalian species (Fevold et al. 1989). For instance, porcine P450c17 readily metabolizes $17 \alpha$-hydroxyprogesterone to androstenedione and metabolizes 17 $\alpha$-hydroxypregnenolone to dehydroepiandrosterone, but the human and bovine enzymes only utilize the latter pathway to any significant degree (Brock \& Waterman 1999, Conley \& Bird 1997, Fevold et al. 1989). These recognized species differences in the competence of $\mathrm{P} 450 \mathrm{cl} 7$ to catalyze 
formation of dehydroepiandrosterone and androstenedione have profound physiological consequences for the control of steroidogenesis in the gonads and adrenals.

To date, studies directly comparing the functional properties of $\mathrm{P} 450 \mathrm{c} 17$ from different species have focused almost exclusively on the substrate-specificity of the 17,20-lyase reaction (Fevold et al. 1989, Lee-Robichaud et al. 1995b, Brock \& Waterman 1999, Arlt et al. 2002, Gilep et al. 2003). The few direct comparisons of turnover rates suggest that human P450c17 hydroxylates pregnenolone at almost twice the rate of the porcine enzyme, but that cleavage of $17 \alpha$-hydroxypregnenolone to dehydroepiandrosterone is 3.5 times faster in reactions with porcine than human P450c17 (Lee-Robichaud et al. 1995a). Human P450c17 hydroxylates progesterone seven times faster than pregnenolone (Brock \& Waterman 1999), even though it can only cleave $17 \alpha$-hydroxypregnenolone effectively, as noted above. Hydroxylation of pregnenolone and progesterone by rat $\mathrm{P} 450 \mathrm{c} 17$ occurs at roughly equal rates, but at half the rate of $17 \alpha-$ hydroxyprogesterone synthesis by human P450c17. Subsequent cleavage of hydroxylated products by rat $\mathrm{P} 450 \mathrm{c} 17$ is much slower, but again, in marked contrast to the human enzyme, occurs at roughly equal rates for $17 \alpha$-hydroxypregnenolone and $17 \alpha$ hydroxyprogesterone (Brock \& Waterman 1999). Although substrate metabolism reduced peroxide formation, there was no obvious correlation between the rate of peroxide formation and substrate turnover rates by the rat and human enzymes (Brock \& Waterman 1999, 2000). The physical basis of these differences in substrate specificity, turnover and peroxide formation remains unknown.

Unlike many other microsomal P450s expressed in the liver, the physical properties of $\mathrm{P} 450 \mathrm{c} 17$, for instance, changes in spin states or the coordination number of the iron heme, have received little or no attention. No studies known to us have examined the direct electrochemistry of these enzymes; nor have any compared physical properties of any kind of the same enzyme from different species. P450s are particularly challenging enzymes as their active sites tend to be well buried within a large protein matrix (Fantuzzi et al. 2004), and membrane-bound proteins are notoriously difficult to examine by direct electrochemistry (Stevens \& Arkin 1999, Hunte et al. 2000). In this study, a pyrolytic graphite (PGE) electrode was modified with a surfactant that both binds strongly to the electrode and mimics a hydrophobic membrane environment. The electron-transfer properties of human, bovine and porcine $\mathrm{P} 450 \mathrm{cl} 7 \mathrm{w}$ were then evaluated in the presence and absence of substrate and these results evaluated in terms of an electron-transfer model for P450c17.

\section{Materials and methods}

\section{Recombinant protein over-expression in Escherichia coli}

The cDNA constructs encoding human, bovine and porcine $\mathrm{P} 450 \mathrm{c} 17$ were generously provided by $\mathrm{Dr}$ Michael Waterman (Department of Biochemistry, Vanderbilt University, Nashville, TN, USA; Barnes et al. 1991, Imai et al. 1993), each modified at the $5^{\prime}$ end for expression in E. coli and His-tagged at the $3^{\prime}$ end before sub-cloning into the pCWOrit vector. Plasmid DNA was used to transform E. coli strain $\mathrm{DH} 5 \alpha$ and a fresh colony was grown overnight in $5 \mathrm{ml} \mathrm{LB}$ broth containing $100 \mu \mathrm{g} \cdot \mu \mathrm{l}^{-1}$ ampicillin. The overnight culture was diluted 1:200 into $200 \mathrm{ml}$ Terrific Broth medium containing $100 \mu \mathrm{g} \cdot \mathrm{\mu l}^{-1}$ ampicillin and $1 \mathrm{mM}$ thiamine in a 21 flask and grown at $37^{\circ} \mathrm{C}$ until the $\mathrm{OD}_{600}$ was $0 \cdot 3-0 \cdot 5$. The culture was induced with $1 \mathrm{mM}$ isopropyl1-thio- $\beta$-D-galactopyranoside (IPTG) in the presence of $0.5 \mathrm{mM} \delta$-amino-levulinic acid (ALA) and grown for $30-48 \mathrm{~h}$ at $30^{\circ} \mathrm{C}$ with gentle shaking. The bacteria were pelleted at $2000 \boldsymbol{g}$, resuspended in $50 \mathrm{ml}$ cold $100 \mathrm{mM}$ Tris/acetate, $\mathrm{pH} 7 \cdot 6,500 \mathrm{mM}$ sucrose, $1 \mathrm{mM}$ EDTA and $0.5 \mathrm{mg} \cdot \mathrm{ml}^{-1}$ lysozyme and stirred slowly on ice for $30 \mathrm{~min}$. After centrifugation at $5000 \mathrm{~g}$ the pellet was resuspended in $10 \mathrm{ml}$ cold $100 \mathrm{mM}$ potassium phosphate, $\mathrm{pH} 7 \cdot 4,6 \mathrm{mM}$ magnesium acetate, $0 \cdot 1 \mathrm{mM}$ dithiothreitol, $20 \%$ glycerol and $0.2 \mathrm{mM}$ phenylmethylsulfonyl fluoride (PMSF), placed in a salt/ice bath and sonicated at $50 \%$ power with six 20 -s bursts, with intermittent cooling, followed by centrifugation for $1 \mathrm{~h}$ at $150000 \mathrm{~g}$. The membrane-containing pellet was solubilized in $12 \mathrm{ml} 50 \mathrm{mM}$ phosphate buffer, $\mathrm{pH} 7 \cdot 4$, $20 \%$ glycerol, $1 \%$ Triton X-100, $0 \cdot 1 \mathrm{mM} \mathrm{PMSF}$ and $40 \mu \mathrm{M}$ pregnenolone for $1 \mathrm{~h}$ on a rotator at $4{ }^{\circ} \mathrm{C}$. The supernatant was collected following a $1 \mathrm{~h} 100000 \mathrm{~g}$ spin. Cytochrome $\mathrm{P} 450$ iron heme content was determined by $\mathrm{CO}$ difference spectra.

\section{Protein purification}

The solubilized membrane fraction was thawed on ice and combined with $8.3 \mathrm{mg}$ imidazole $(10 \mathrm{mM}$ final $)$ and $2 \mathrm{ml} \mathrm{Ni}{ }^{2+}$-nitrilotriacetate agarose for $2 \mathrm{~h}$ at $4{ }^{\circ} \mathrm{C}$ on a rotator. The resin was packed by gravity flow at room temperature into a $5 \mathrm{ml}$ disposable column and washed with four column volumes of $20 \mathrm{mM}$ imidazole and then four column volumes of $40 \mathrm{mM}$ imidazole in solubilisation buffer (comprising $50 \mathrm{mM}$ potassium phosphate, $\mathrm{pH} 7 \cdot 4,20 \%$ glycerol, $1 \%$ Triton X-100, $0 \cdot 1 \mathrm{mM}$ PMSF and $40 \mu \mathrm{M}$ pregnenolone). The His-tagged protein was eluted in a total of $3 \mathrm{ml}$ of $200 \mathrm{mM}$ imidazole in solubilisation buffer and dialysed overnight against 11 of $100 \mathrm{mM}$ phosphate buffer, pH 7.4, 20\% glycerol, 2-mercaptoethanol and $1 \mathrm{mM}$ CHAPS. The iron heme content of the $\mathrm{P} 450$ s was again measured by $\mathrm{CO}$ 
difference spectra and total $\mathrm{P} 450$ protein content was determined using the BCA protein reagent and the proteins were separated on an 8\% SDS/PAGE gel and visualized using GelCode Blue stain reagent. Purification yielded enzyme preparations containing $10-12 \mathrm{nmol}$ $\mathrm{P} 450 / \mathrm{mg}$ protein. There was little or no $\mathrm{P} 420$ by spectral analysis and turnover rates of up to $50 \mathrm{~min}^{-1}$ were observed at substrate saturation.

\section{CO difference spectra}

The dialysed eluate was diluted 1:1 in dialysis buffer and divided between the sample and reference cuvettes for spectral analysis on a split-beam Shimadzu 2401 spectrophotometer. A baseline was recorded between 400 and $500 \mathrm{~nm}$. The sample cuvette was saturated with $\mathrm{CO}$, a few crystals of sodium dithionite $\left(\mathrm{Na}_{2} \mathrm{~S}_{2} \mathrm{O}_{4}\right)$ were mixed by inversion into both the reference and sample cuvettes and the spectra were again recorded. The cytochrome $\mathrm{P} 450$ concentration was calculated as $\left(\mathrm{A}_{450}-\mathrm{A}_{490}\right) / 0 \cdot 091=\mathrm{nmol} \cdot \mathrm{ml}^{-1}$.

\section{Materials}

Didodecyldimethylammonium bromide (DDAB;>99\%) was purchased from Sigma and used without further purification. All other chemicals were analytical reagent grade and were used without further purification. Milli-Q water was used both as a solvent and in all washing steps. Solutions were buffered in the $\mathrm{pH}$ range 5.8-8.2 with phosphate buffer. The $\mathrm{pH}$ was determined using a calibrated Radiometer PHM210 pH meter.

\section{Electrochemical apparatus and procedures}

All experiments were undertaken in a nitrogen-filled glove box to alleviate complications associated with oxygen catalysis and subsequent hydrogen peroxide formation. Cyclic voltammograms were recorded using a BAS Model 100B electrochemical analyser, and were obtained at least four times with fresh buffer and different electrodes. Scan rates typically varied between 2 and $1500 \mathrm{mV} \cdot \mathrm{s}^{-1}$. Voltammetric data were obtained using an edge-oriented PGE electrode; radius, $\sim 2.0 \mathrm{~mm}$. Before each experiment, the electrode surface was polished with an alumina/water slurry (alumina particle size was $1 \mu \mathrm{m}$, followed by $0.3 \mu \mathrm{m}$ ), washed, and sonicated for $1 \mathrm{~min}$ to remove adsorbed alumina. The reference and counter electrodes were $\mathrm{Ag} / \mathrm{AgCl}(3 \mathrm{M} \mathrm{KCl})$ and platinum wire respectively. The reference electrode was regularly calibrated against the $\left[\mathrm{Fe}(\mathrm{CN})_{6}\right]^{3-/ 4-}$ couple in $1 \mathrm{M} \mathrm{KNO}_{3}$ (Johnson et al. 2003). Midpoint potentials $\left(E_{\text {mid }}\right)$ were calculated as the average of the oxidation $\left(E \mathrm{p}_{\mathrm{a}}\right)$ and reduction $\left(E \mathrm{p}_{\mathrm{c}}\right)$ peaks, the peak separation $(\Delta E)$ was calculated as the difference between $E \mathrm{p}_{\mathrm{a}}$ and $E \mathrm{p}_{\mathrm{c}}$, and the peak current ratio $\left(i \mathrm{p}_{\mathrm{c}} / i \mathrm{p}_{\mathrm{a}}\right)$ was calculated by dividing the cathodic peak current $\left(i \mathrm{p}_{\mathrm{c}}\right)$ by the anodic peak current $\left(i \mathrm{p}_{\mathrm{a}}\right)$. Potentials have been corrected to the normal hydrogen electrode.

A typical experiment proceeded as follows: a solution of DDAB was applied to the clean electrode surface $(1 \mu \mathrm{l}$ of a $0 \cdot 1 \mathrm{M}$ stock in chloroform) and allowed to dry. The protein $(3 \mu \mathrm{l}$; stock solutions were $3-5 \mu \mathrm{M})$ was then applied to the electrode surface, and the electrode allowed to stand for 2 min before immersing into the buffered solution at the required $\mathrm{pH}$. Phosphate buffer $(0 \cdot 1 \mathrm{M})$ was typically used, but the influence of ionic strength was also evaluated by examining voltammetric behavior at several $\mathrm{pH}$ values in $1.0 \mathrm{M}$ phosphate buffer.

Substrate binding was evaluated in three different ways at a variety of concentrations between $10 \mu \mathrm{M}$ and $100 \mathrm{mM}$ in $1 \%$ DMSO, with comparable results. (1) The electrode was modified with a protein film as above and then placed into a solution of phosphate buffer containing the desired substrate. (2) An electrode was modified with a protein film as described above, and then the electrode was left to stand for 5-15 min prior to $3 \mu \mathrm{l}$ of the substrate solution being added. The film was then allowed to dry for $\sim 10 \mathrm{~min}$ before being placed into a buffered solution. (3) Protein $(10 \mu \mathrm{l})$ was incubated with a solution of the substrate at $4{ }^{\circ} \mathrm{C}$ for $10 \mathrm{~min}$ (incubation periods up to $16 \mathrm{~h}$ were also attempted), before being applied to the electrode surface as per a typical experiment. In each case, cycling for several hours revealed no significant changes in midpoint potential.

\section{Results}

A thin film of purified cytochrome $\mathrm{P} 450 \mathrm{c} 17$ was immobilized at an edge-oriented PGE electrode pretreated with DDAB. DDAB is a cationic surfactant comprising a positively charged dimethyl-ammonium head group capable of electrostatically interacting with negatively charged surface residues at a freshly polished PGE surface, and a hydrophobic didodecyl tail-group moiety capable of mimicking the environment of a biological membrane. Cyclic voltammograms of a PGE electrode modified with a film of DDAB in the absence of $\mathrm{P} 450$ revealed no redox response in the potential range considered. However, voltammograms of the $\mathrm{PGE} / \mathrm{DDAB} / \mathrm{P} 450 \mathrm{c} 17$ film were redox active and showed good signal-to-noise responses for scan rates between 2 and $1500 \mathrm{mV} \cdot \mathrm{s}^{-1}$ (Fig. 1a). The cyclic voltammograms obtained for the human, bovine and porcine forms of $\mathrm{P} 450 \mathrm{c} 17$ were all typical of that expected for direct electron exchange between the electrode and the iron heme 'active site' (Rusling 1998, Aguey-Zinsou et al. 2003, Fleming et al. 2003) with midpoint potentials $\left(E_{\text {mid }}\right)$ of $-48,-54$ and $-3 \mathrm{mV}$ 

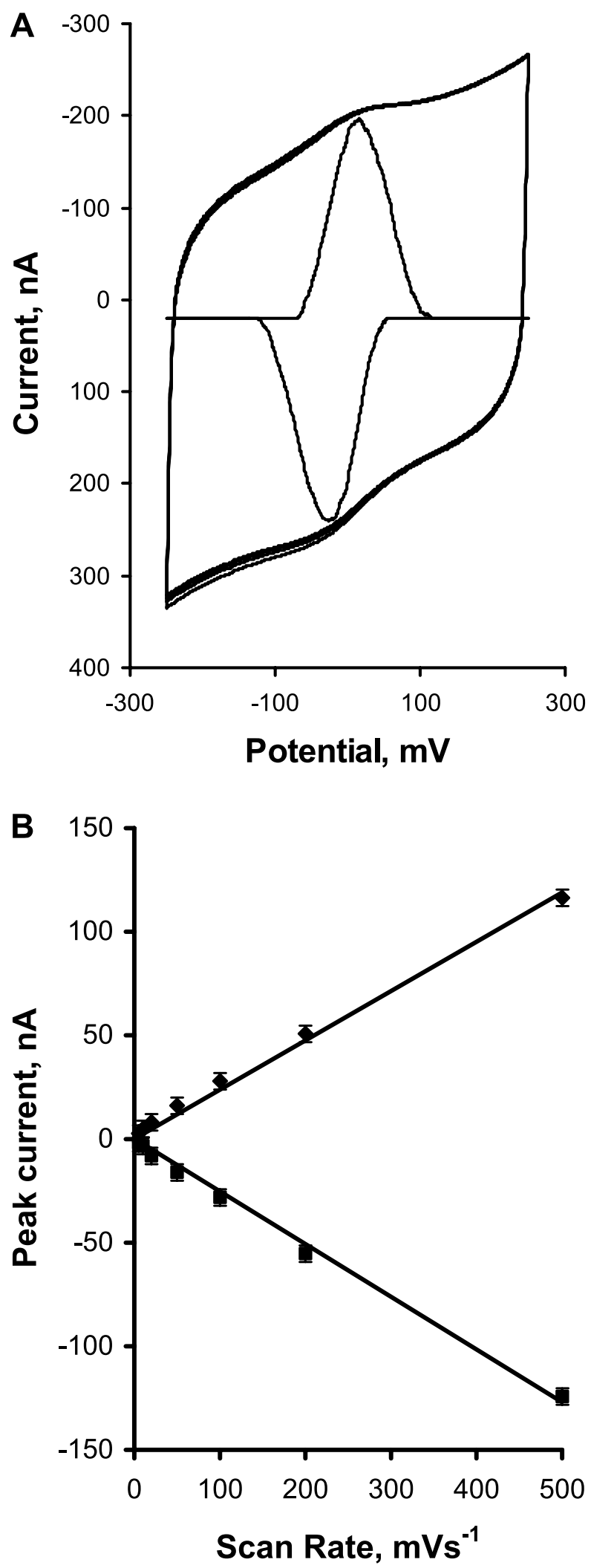

respectively $(\mathrm{pH} 7 \cdot 4,0 \cdot 1 \mathrm{M}$ phosphate buffer). Cyclic voltammograms differed slightly between the first few cycles as the molecular structure at the surface appeared to reorganize into an optimal configuration, after which reproducible voltammograms could be obtained for several hours, indicating a stable, active enzyme film. The surface reorganization did not influence any of the measured electrochemical parameters of interest; $E_{\text {mid }}$, $\Delta E, i \mathrm{p}_{\mathrm{c}} / i \mathrm{p}_{\mathrm{a}}$ and $k_{\mathrm{s}}$ were consistent throughout. The small changes primarily relate to variation in the capacitive currents and these are typical for electrochemistry of thin films containing biological components (Armstrong 1990, Armstrong et al. 1997). Typically, the PGE/ $\mathrm{DDAB} / \mathrm{P} 450 \mathrm{c} 17$ films were used over $\sim 3 \mathrm{~h}$ of continuous cycling between the ferric and ferrous forms, suggesting that the film integrity, composition and amount of bound protein remains constant throughout this period (Fig. la). Figure $1 \mathrm{~b}$ highlights a linear relationship between scan rate $(v)$ and peak current (ip), indicative of an immobilized redox-active species with little or no influence of mass transport of redox-active material away from or towards the electrode. The 'reversibility' of electron-transfer process was evaluated by dividing the cathodic current by the anodic current $\left(i \mathrm{p}_{\mathrm{c}} / i \mathrm{p}_{\mathrm{a}}\right)$, revealing a slight dominance of the cathodic wave, typically $\sim 5 \%$ greater than the anodic current. The magnitude of the Faradaic current was influenced by the amount of immobilized protein applied and also by the number of alternate layers of DDAB and $\mathrm{P} 450$ applied to the electrode. Optimal peak currents were obtained using two distinct layers of the DDAB/P450 repeating unit. Additional layers appeared to have no impact on the observed peak currents.

The surface coverage $(\Gamma)$ of the electroactive, immobilized protein for a single DDAB/P450 layer was evaluated by integration of the anodic and/or cathodic peak employing the relationship $Q=F A \Gamma$, where $Q$ is the charge, obtained by integration of the oxidative voltammogram, $F$ is Faraday's constant and $A$ is the electrode area. The electroactive surface coverage was calculated to be $9 \cdot 21 \times 10^{-12} \mathrm{~mol} \cdot \mathrm{cm}^{-2}$. Assuming that individual $\mathrm{P} 450 \mathrm{c} 17$ molecules retain their fundamental geometry when they bind to the electrode, a single monolayer of $\mathrm{P} 450$ affords a surface coverage of

Figure 1 (a) Typical cyclic voltammograms of porcine P450c17 obtained at a PGE/DDAB electrode in the absence of oxygen. The stability of the film is highlighted, with scans taken at hourly intervals after first putting the electrode into buffer. Scans at 1, 2, 3, 4, 5 and $10 \mathrm{~h}$ are overlaid (outer traces). Inner trace is the voltammogram after removal of capacitive (baseline) current, showing only Faradaic current. Buffer was $0.1 \mathrm{M}$ potassium phosphate, $\mathrm{pH} 7.4$. Scan rate, $50 \mathrm{mV} \cdot \mathrm{s}^{-1}$. (b) Variation of peak currents (ipa, $\bullet$ and ipc, $\square$ ) with scan rate $(v)$ for bovine $\mathrm{P} 450 \mathrm{c} 17$. The linear relationship indicates that the protein is confined as a thin film at the electrode surface. Buffer was $0.1 \mathrm{M}$ potassium phosphate, $\mathrm{pH} 7.4$. 


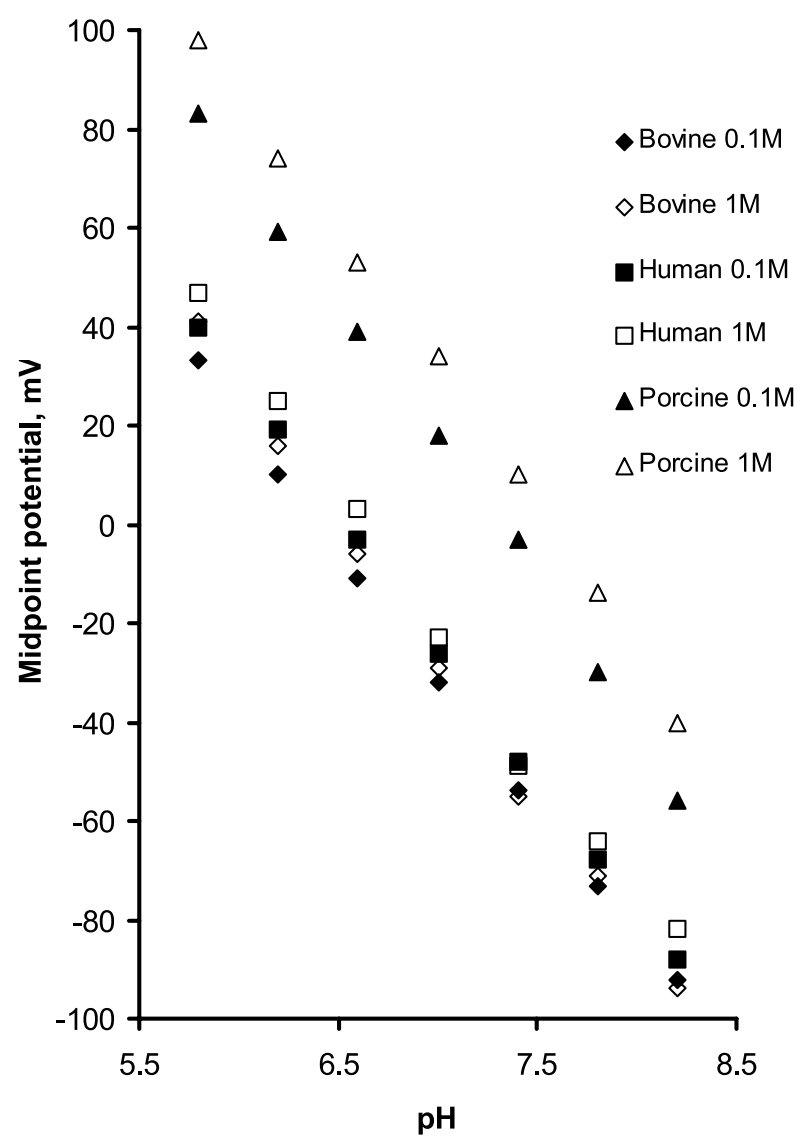

Figure 2 Midpoint potentials of human, bovine and porcine P450c17 adsorbed at a PGE/DDAB electrode as influenced by $\mathrm{pH}$ and ionic strength. The porcine midpoint potential differs to the human and bovine forms at each $\mathrm{pH}$ value considered and is shifted by ionic strength. The slopes of each plot, in $\mathrm{mV}$ per $\mathrm{pH}$ unit are: bovine $0.1 \mathrm{M}(\diamond),-52.1$; bovine $1 \mathrm{M}(\diamond),-56.1$; human $0.1 \mathrm{M}(\mathbf{\square}),-53 \cdot 8$; human $1 \mathrm{M}(\square),-55 \cdot 1$; porcine $0.1 \mathrm{M}(\Delta),-56 \cdot 9$; porcine $1 \mathrm{M}(\Delta),-56.5$.

$1 \cdot 01 \times 10^{-11} \mathrm{~mol} \cdot \mathrm{cm}^{-2}$, based on the crystal structure dimensions of P450 cam (Lei et al. 2000). Although only an approximate calculation, this suggests that around $91 \%$ of adsorbed protein contributes to the electrochemical signal.

For all species examined here, the $\mathrm{P} 450 \mathrm{c} 17$ reduction potentials were influenced by both $\mathrm{pH}$ and the ionic strength $(I)$ of the phosphate buffer solution (Fig. 2). Variation of $\mathrm{pH}$ led to a shift in $E_{\text {mid }}$ of between -51 and $-57 \mathrm{mV}$ per $\mathrm{pH}$ unit, close to the theoretical value of $-59 \mathrm{mV}$ per $\mathrm{pH}$ unit predicted for the coupling of a single proton transfer to the electron-transfer event from the Nernst equation. This trend was observed for the human, bovine and porcine samples, and was comparable at 4 and $20^{\circ} \mathrm{C}$. Interestingly, this effect was consistent in the presence and absence of substrate. The influence of $I$ was less dramatic, with a 10 -fold increase in $I(0 \cdot 1-1 \mathrm{M}$ phosphate buffer), prompting an anodic

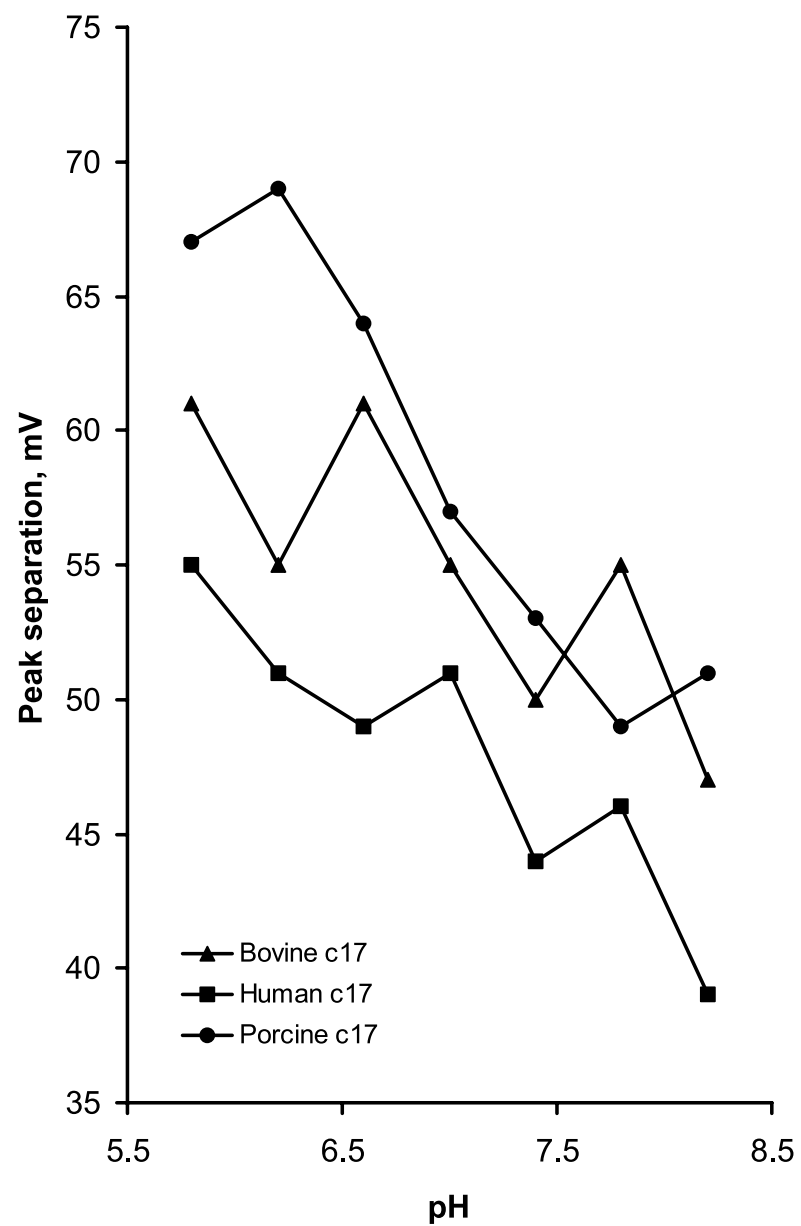

Figure 3 Influence of $\mathrm{pH}$ value on peak separation $(\Delta E)$ for bovine ( $\boldsymbol{\Delta}$ ), human ( $)$ and porcine ( $)$ P450c17 adsorbed at a PGE/DDAB electrode. In each case, the midpoint potential was minimized at a higher $\mathrm{pH}$, perhaps reflecting efficiency of electron transfer. lonic strength, $0.1 \mathrm{M}$; scan rate, $50 \mathrm{mV} \cdot \mathrm{s}^{-1}$.

shift of $\sim 15 \mathrm{mV}$ for the porcine $\mathrm{P} 450 \mathrm{c} 17$ and smaller changes for the bovine and human forms. The influence of $I$ on the porcine sample was approximately linear across the $\mathrm{pH}$ range considered; all three species showed the greatest anodic shift in $E_{\text {mid }}$ at higher ionic strength $(I=1 \cdot 0)$ and at low $\mathrm{pH}(\mathrm{pH} 5 \cdot 8)$, the lowest $\mathrm{pH}$ value examined here.

Each of the P450c17 isoforms showed generally faster electron-transfer rates at higher $\mathrm{pH}$ (Fig. 3). The electron-transfer rate constant $\left(k_{\mathrm{s}}\right)$ was estimated (Laviron 1979) for each of the P450c17 (human, bovine and porcine) enzymes and found to be very similar; 164, 157 and $153 \mathrm{~s}^{-1}$ respectively. It should be noted that these rate constants were measured in the absence of oxygen and thus do not necessarily reflect enzymic activity rates during substrate turnover.

P450c17 has several well-known substrates, including progesterone, pregnenolone, $17 \alpha$-hydroxypregnenolone 
and 17a-hydroxyprogesterone. These substrates were used to evaluate the influence of substrate binding on the redox properties of $\mathrm{PGE} / \mathrm{DDAB} / \mathrm{P} 450 \mathrm{c} 17$-modified electrodes. Interestingly, the voltammetric parameters defining the redox process $\left(E_{\text {mid }}, \Delta E, i \mathrm{p}_{\mathrm{c}} / i \mathrm{p}_{\mathrm{a}}, k_{\mathrm{s}}\right)$ were unchanged over a wide range of experimental conditions, including the presence of substrate. This may indicate that, in the absence of oxygen, the substrate docks with the enzyme some distance from the active site, or alternatively that substrate binding has a negligible effect on the electronic environment of the heme redox centre at the active site of $\mathrm{P} 450 \mathrm{c} 17$.

\section{Discussion}

We report for the first time direct (without mediators) electrical communication between an artificial electron donor (an electrode) and cytochrome P450c17. Three important observations were made. Firstly, the redox potential of all P450c17 enzymes investigated was considerably higher than that of the microsomal redox partner protein NADPH-cytochrome P450 oxidoreductase. In itself, this finding suggests that no increase in redox potential is required to facilitate enzyme reduction. Secondly, no shift in redox potential was observed upon the addition of known substrates. Thirdly, the porcine P450c17 exhibited a much higher redox potential than either the human or bovine enzyme. This suggests that there are species differences in charge density surrounding the iron heme moiety, despite the fact that molecular modelling predicts a highly conserved active site (Auchus \& Miller 1999, Burke et al. 1997). Charged residues near the iron heme may well influence substrate orientation, determine accessibility to activated oxygen or directly influence oxygen insertion by some as yet undetermined manner favouring $17 \alpha$-hydroxyprogesterone only for the porcine P450c17.

A point mutation selectively altering 17,20-lyase activity of human P450c17 was recently reported to involve neutralization of a positively charged glutamate residue predicted to lie near the heme in the active site (Sherbet et al. 2003). While implicating charged residues in 17,20-lyase activity, this residue is conserved across mammalian species and is unlikely to explain the species differences in substrate specificity. Our electrochemical results are also consistent with the notion that the ferrous form of the porcine enzyme is stabilized to a greater degree than the human or bovine forms. Lewis and Hlavica (2000) described the influence of the local dielectric constant and protein radius relative to that of the heme moiety on the predicted redox potentials. It is possible that the porcine $\mathrm{P} 450 \mathrm{c} 17$ is more hydrophobic overall at the active site compared with the human and bovine isoforms and that this effect results in a stabilization of the ferrous form. How this influences substrate binding and/or affinity is unclear at present, since no shift in redox potential was observed with any of the substrates investigated here. These observations should direct future site-directed mutagenesis to target charged residues predicted to be near the heme in the active site to identify those residues involved in species-specific substrate preferences of mammalian P450c17 enzymes.

The redox characteristics of $\mathrm{P} 450 \mathrm{~s}$ have been considered for over 20 years, but unmediated electron transfer has only been obtained for a few species and under limited experimental conditions. During the past decade, direct electrochemistry has been obtained at edge-plane PGE without redox mediators (Kazlauskaite et al. 1996), in lipid films (Ivanov et al. 2001, Zhang et al. 1997), using sol-gels (Iwuoha et al. 2000), in colloidal clay (Lei et al. 2000) and with surface-confined promoters (Aguey-Zinsou et al. 2003, Lvov et al. 1998, Munge et al. 2003). Numerous other redox studies have examined $\mathrm{P} 450$ s in solution. Taken together the redox characteristics of P450 enzymes vary widely with experimental conditions, emphasizing the importance of reproducing more physiological conditions during electrochemical measurements. Modification of electrodes with DDAB provides a pseudo-membrane surface and may be more reflective of the environment of membrane-bound P450s. Our results suggest that some alignment or re-orientation ('bedding down') occurs initially at the electrode surface. P450s are predicted to have surfaceexposed hydrophobic patches (Graham \& Peterson 1999, Peterson \& Graham 1998) and thus may be capable of adopting more than one favourable orientation at the electrode surface. Theoretically, a one-electron transfer of an immobilized redox active species in a homogenous orientation gives rise to a peak width at half height $\left(\omega^{1 / 2}\right)$ of $90 \mathrm{mV}$ (Laviron 1979). The broadness of the redox waves for all the P450c17 samples $\left(\omega^{1 / 2} \sim 130 \mathrm{mV}\right)$ suggests that several stable enzyme orientations may contribute to the overall electrochemical response observed here.

The $\mathrm{P} 450 \mathrm{c} 17 E_{\text {mid }}$ was found to vary linearly with $\mathrm{pH}$ over the range $5 \cdot 8-8 \cdot 2$, with the potential shift between -52 and $-57 \mathrm{mV}$ per $\mathrm{pH}$ unit, depending on species and ionic strength. These values indicate that a single proton transfer is coupled to the electron-transfer event, a phenomenon for which a potential shift of $-59 \mathrm{mV}$ per $\mathrm{pH}$ unit is predicted by the Nernst equation. Similar $\mathrm{pH}$ profiles have been observed for other $\mathrm{P} 450$ s, with the dependence of $-33 \mathrm{mV}$ per $\mathrm{pH}$ unit for P450BM3 (Fleming et al. 2003), and $-52 \mathrm{mV}$ per $\mathrm{pH}$ unit for P4502C9 (Johnson et al. 2005) at a DDAB-modified electrode. This $\mathrm{pH}$ profile has been attributed to protonation of either an amino acid residue in the immediate vicinity of the active site or a functional group coordinated to the iron heme (Aguey-Zinsou et al. 
2003), and is a fundamental requirement for the completion of the catalytic cycle, providing the proton required for a hydroxylation reaction. However, the nature of the functional group involved in the proton transfer at the active site remains unclear, as its $\mathrm{p} K_{\mathrm{a}}$ lies outside of the $\mathrm{pH}$ range used in this study. A similar conclusion was reported for $\mathrm{P} 450$ cin (Aguey-Zinsou et al. 2003), where the $\mathrm{p} K_{\mathrm{a}}$ was thought to lie at a value $>10$, indicating that reduction from ferric to ferrous liberates a strong base close to the heme active site. The redox potentials of all cytochromes studied to date vary between -400 and $+400 \mathrm{mV}$, a magnitude equivalent to changing the $\mathrm{p} K_{\mathrm{a}}$ of a functional group by $\sim 14 \mathrm{pH}$ units (Mao et al. 2003). Thus, the high $\mathrm{p} K_{\mathrm{a}}$ for P450c17 enzymes suggested by the current data are not unique.

The $\mathrm{pH}$ profiles for the three P450c17 enzymes examined in this study were also very similar in the presence and absence of substrate. This suggests that the coordination number of the iron heme probably remains constant with or without substrate. The absence of any shift in redox potential with substrate suggests that the spin-state conversion for the ferric ion upon substrate binding may occur independently of redox potential. Indeed, the correlation between $E_{\text {mid }}$ and spin equilibrium has been predicted to be a relatively small effect (Cant et al. 1975), notably less significant than inductive or substituent effects that are often observed (Sligar 1976, Fisher \& Sligar 1985). Redox potentials are predominantly influenced by the binding constants to both oxidized and reduced forms of the enzyme. Consequently, it has been proposed that the anodic substrate shift observed for some P450s may simply indicate that the substrate binds with stronger affinity to the reduced form of the enzyme, raising the $E_{\text {mid }}$. Conversely, the absence of a shift may simply indicate that the substrate does not preferentially bind to either the oxidized or the reduced forms of the enzyme, rather with equal affinity to both forms (Rusling 1998). The possible relevance of a substrate-induced change in $E_{\text {mid }}$ has been questioned (Fleming et al. 2003). Since these experiments require anaerobic conditions, oxygen binding to the heme in vivo would surely influence redox potential, with or without substrate present, as observed for binding of $\mathrm{CO}$ to the iron heme in the absence of substrate. This is consistent with biochemical studies on several purified rat liver P450s from which it was concluded that no correlation between spin state of the iron heme or kinetics of ferric reduction could explain the differences observed (Guengerich 1983, Backes \& Eyer 1989, Eyer \& Backes 1992).

Substrate docking has also been proposed to act as a thermodynamic trigger for P450 turnover, inducing an anodic shift in redox potential of the $\mathrm{P} 450$ from below to above that of the physiological donor (Sligar 1976, Reipa et al. 2002). However, no substrate-induced anodic shift was observed with any of the P450c17 enzymes in the current study, and this may not be true for all P450s. Direct electrochemical studies with P450 cam, P450 scc, P450 3A4 and P450 cin have not universally confirmed a substrate-induced shift in redox potential (Table 1), despite spin conversion observed in some cases (Yamazaki et al. 1996). These apparent discrepancies might be explained if either (i) P450 conformation in the presence of lipids or surfactants is different to that in solution, possibly influencing the interaction of P450c17 with substrate (French et al. 1980, Miwa \& Lu 1981, Ruckpaul et al. 1982, Omata et al. 1987, Imaoka et al. 1992, Voznesensky \& Schenkman 1994, Yun et al. 1998) or (ii) the substrate binds at a location remote from the redox 'active site' with minimal change in local electronic structure. Certainly caution must be exercised when comparing results across studies using different methodologies and experimental conditions. The redox potential measured for P450 cam shifts by $130 \mathrm{mV}$ upon camphor binding in solution (Sligar \& Gunsalas 1976), just $23 \mathrm{mV}$ at a hydrophobic electrode (Iwuoha et al. 2000) and none at all at a clay-modified electrode (Lei et al. 2000). Nevertheless, immobilized P450 enzymes turn over under aerobic conditions in many of these cases (Iwuoha et al. 2000, Estavillo et al. 2003, Joseph et al. 2003, Munge et al. 2003, Fantuzzi et al. 2004, Immoos et al. 2004). Crystallographic evidence documents marked changes in P450 structure upon ligand binding; of P4502C9 with warfarin (Williams et al. 2003) and P450 2B4 with imidazole (Scott et al. 2004). For these xenobiotic $\mathrm{P} 450$ s, there may be multiple substrate-binding modes (Williams et al. 2003, 2004), only some of which might alter redox potential or spin state. However, with the narrow substrate specificity observed for $\mathrm{P} 450 \mathrm{c} 17$ this is less likely.

Interestingly, increasing the ionic strength $(I)$ of the phosphate buffer also had a greater effect on the porcine isoform than either the human or bovine isoforms. Increasing $I$ from 0.1 to $1.0 \mathrm{M}$ induced a $15-20 \mathrm{mV}$ shift in $E_{\text {mid }}$ (porcine) compared with only $0-7 \mathrm{mV}$ (human or bovine). The effect of $I$ for $\mathrm{P} 450 \mathrm{c} 17$ has been investigated previously, in particular its role in the interaction with $\mathrm{P} 450$ reductase (Jenkins \& Waterman 1998), where an increase in $I$ led to a decrease in P450c17 activity, attributed by the authors to disruption of electrostatic interactions needed for electron delivery to the P450 enzyme. In this study, experiments were undertaken above and below the $\mathrm{p} I$ of $\mathrm{P} 450 \mathrm{c} 17$ of $\sim 6.5$ (Kuwada 1999, Kuwada et al. 2001). It seems likely that individual charged amino acids near the heme group influence the $E_{\text {mid }}$ of P450c17; however, the anodic shift we observed with increasing $I$ is unusual, since most proteins exhibit a cathodic shift with increasing $I$ (Alberty 2001). Data obtained in this work using three species of P450c17 enzymes, together with previous reports on P450 scc (Nicolini et al. 2001) and also a 


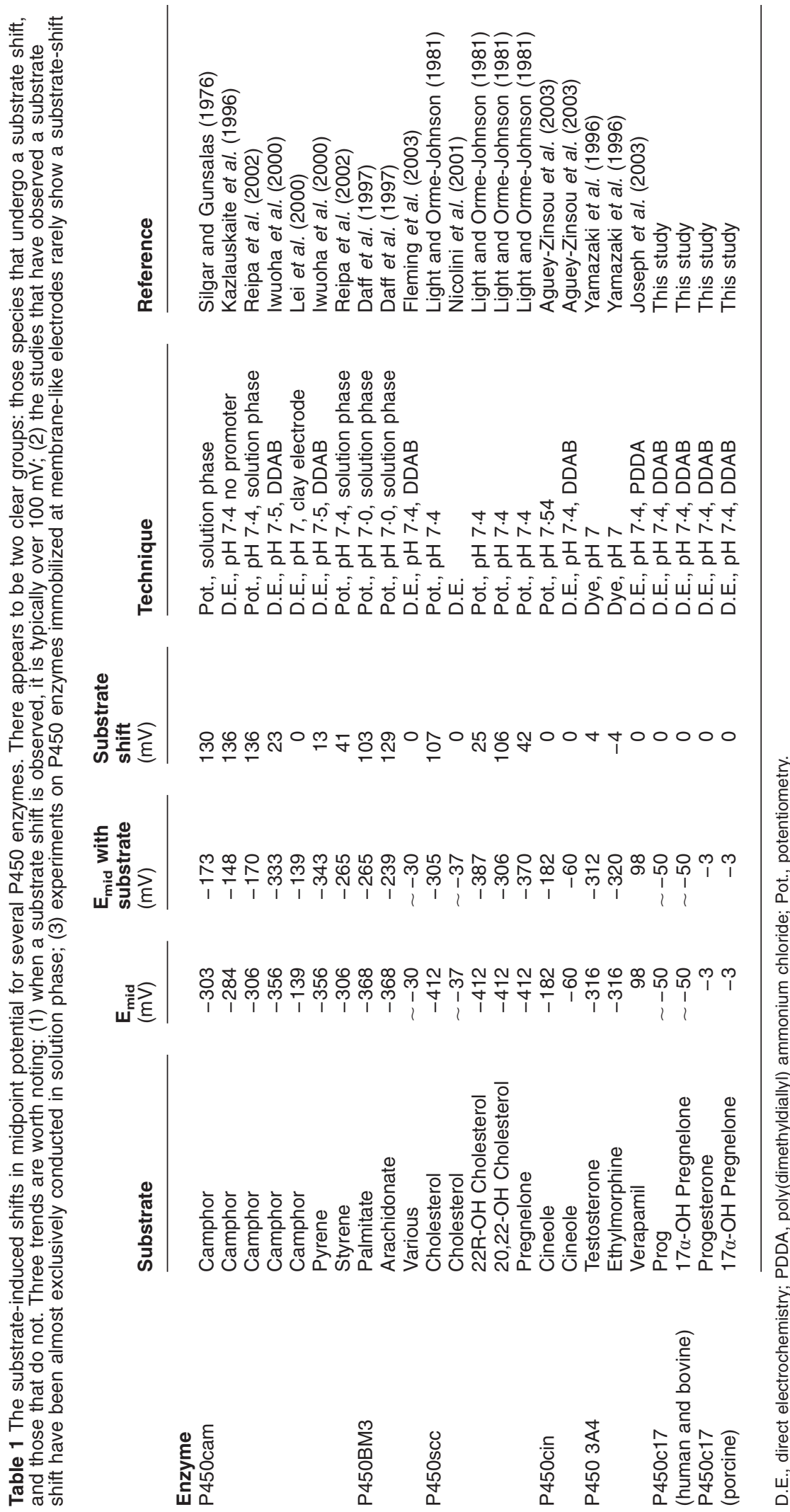


cytochrome $b_{5}$ mutant (Reid et al. 1984), are consistent with the ferrous (reduced) state being stabilized at higher $I$, indicating an decrease in negative charge near the heme group. Additionally, all of the P450c17 enzymes examined in this study exhibited rapid but very similar rates of electron transfer: $k_{\mathrm{s}} \sim 150 \pm 30 \mathrm{~s}^{-1}$ at $\mathrm{pH} 7 \cdot 4$. Rates from electron donors to $\mathrm{P} 450$ s vary apparently over a large range, from $0 \cdot 45 \mathrm{~s}^{-1}$ for P450 scc (Nicolini et al. 2001) to $25-84 \mathrm{~s}^{-1}$ for P450 cam (Fisher \& Sligar 1985, Zhang et al. 1997, Mouro et al. 1999, Lei et al. 2000) and $223 \mathrm{~s}^{-1}$ for P450BM3 (Fleming et al. 2003). Interestingly, in the current study electron-transfer rates generally increased with $\mathrm{pH}$ (data not shown), indicating that $\mathrm{P} 450 \mathrm{c} 17$ turnover should be maximized at high $\mathrm{pH}$ as observed previously for $\mathrm{P} 450 \mathrm{cam}$ and myoglobin (Munge et al. 2003). However, optimal P450c17 $17 \alpha$-hydroxylase activity is obtained at $\mathrm{pH} 8.25$ for pig testicular microsomes (Swinney \& Mak 1994) and at 7.7 for human testicular microsomes (Hosaka et al. 1980). These data suggest that electron-transfer rates do not limit substrate turnover, consistent with data suggesting that $\mathrm{C}-\mathrm{H}$ bond breakage is at least partially limiting in many mammalian $\mathrm{P} 450$ reactions (Guengerich et al. 2004).

In summary, we have measured the redox potentials for human, bovine and porcine P450c17 at graphite electrodes modified with the surfactant DDAB. A linear dependence of the redox potentials with $\mathrm{pH}$ was observed, consistent with a one-electron/proton-coupled transfer process. Increased $I$ of the buffer solution led to an anodic shift in midpoint potential for all species, consistent with a stabilization of the reduction process. Measured values for the midpoint potentials were similar for the human and bovine enzymes, but was significantly higher for porcine $\mathrm{P} 450 \mathrm{c} 17$ at all $\mathrm{pH}$ values, perhaps identifying differences in charge density, and stabilization of the reduced and oxidized forms of the enzymes. How the noted variations in redox potential influence known differences in substrate utilization requires further investigation.

\section{Acknowledgements}

We thank Jo Corbin and Francisco Moran Messen for expertise in the purification of the cytochrome $\mathrm{P} 450 \mathrm{c} 17$ enzymes. This work was supported in part by NHMRC grant no. 284421 and NIH grant HDO 48797. The authors declare that there is no conflict of interest that would prejudice the impartiality of this scientific work.

\section{References}

Aguey-Zinsou K-F, Bernhardt PV, De Voss JJ \& Slessor KE (2003) Electrochemistry of P450 cin: new insights into P450 electron transfer. Fournal of the Chemical Society, Chemical Communications $3418-419$.

Alberty RA (2001) Standard apparent reduction potentials for biochemical half reactions as a function of $\mathrm{pH}$ and ionic strength. Archives of Biochemistry and Biophysics 389 94-109.

Arlt W, Martens JW, Song M, Wang JT, Auchus RJ \& Miller WL (2002) Molecular evolution of adrenarche: structural and functional analysis of $\mathrm{p} 450 \mathrm{c} 17$ from four primate species. Endocrinology 143 4665-4672.

Armstrong FA (1990) Probing metalloproteins by voltammetry. In Structure and Bonding, pp 139-221. Berlin: Springer-Verlag.

Armstrong F, Heering H \& Hirst J (1997) Reactions of complex metalloproteins studied by protein-film voltammetry. Chemical Society Reviewes 26:169-179.

Auchus RJ \& Miller WL (1999) Molecular modeling of human P450c17 (17 alpha-hydroxylase/17,20-lyase): insights into reaction mechanisms and effects of mutations. Molecular Endocrinology 13 1169-1182.

Backes WL \& Eyer CS (1989) Cytochrome P-450 LM2 reduction: Substrate effects on the rate of reductase-LM2 association. Fournal of Biological Chemistry 264 6252-6259.

Barnes HJ, Arlotto M, P. and Waterman MR (1991) Expression and enzymic activity of recombinant cytochrome P450 17 a-hydroxylase in Escherichia coli. PNAS 88 5597-5601.

Brock BJ \& Waterman MR (1999) Biochemical differences between rat and human cytochrome $\mathrm{P} 450 \mathrm{c} 17$ support the different steroidogenic needs of these two species. Biochemistry 38 1598-1606.

Brock BJ \& Waterman MR (2000) The use of random chimeragenesis to study structure/function properties of rat and human P450c17. Archives of Biochemistry and Biophysics 373 401-408.

Burke DF, Laughton CA \& Neidle S (1997) Homology modelling of the enzyme P450 17 alpha-hydroxylase/17,20-lyase-a target for prostate cancer chemotherapy-from the crystal structure of P450BM-3. Anticancer Drug Design 12 113-123.

Cant R, Hendrickson AR, Martin RL \& Rohde NM (1975) Tris(dithiocarbamateo) Complexes of Iron(II), Iron(III) and Iron(IV). An Electrochemical Study. Inorganic Chemistry 14 1894-1902.

Conley AJ \& Bird IM (1997) The role of cytochrome P450 17 alpha-hydroxylase and 3 beta-hydroxysteroid dehydrogenase in the integration of gonadal and adrenal steroidogenesis via the delta 5 and delta 4 pathways of steroidogenesis in mammals. Biology of Reproduction 56 789-799.

Daff SN, Chapman SK, Turner KL, Holt RA, Govindaraj S, Poulos TL \& Munro AW (1997) Redox control of the catalytic cycle of flavocytochrome P450BM3. Biochemistry 36 13816-13823.

Estabrook RW (2003) A passion for P450s (rememberances of the early history of research on cytochrome P450). Drug Metabolism and Disposition 31 1461-1473.

Estavillo C, Lu Z, Jansson I, Schenkman JB \& Rusling JF (2003) Epoxidation of styrene by human cyt P450 1A2 by thin film electrolysis and peroxide activation compared to solution reactions. Biophysical Chemistry 104 291-296.

Eyer CS \& Backes WL (1992) Relationship between the rate of reductase-cytochrome $\mathrm{P} 450$ complex formation and the rate of first electron transfer. Archives of Biochemistry and Biophysics. 293 231-240.

Fantuzzi A, Fairhead M \& Gilardi G (2004) Direct electrochemistry of immobilised human cytochrome P4502E1. Fournal of the American Chemical Society 126 2040-5041.

Fevold HR, Lorence MC, McCarthy JL, Trant JM, Kagimoto M, Waterman MR \& Mason JI (1989) Rat p450 17 alpha from testis: characterization of a full-length cDNA encoding a unique steroid hydroxylase capable of catalyzing both delta4- and delta 5-steriod-17,20-lyase reactions. Molecular Endocrinology 3 968-975.

Fisher MT \& Sligar SG (1985) Control of heme protein redox potential and reduction rate: linear free energy relation between 
potential and ferric spin state equilibrium. Fournal of the American Chemical Society 107 5018-5019.

Fleming BD, Tian Y, Bell SG, Wong L-L, Urlacher V \& Hill HAO (2003) Redox properties of cytochrome P450BM3 measured by direct methods. European Fournal of Biochemistry $2704082-4088$.

French JS, Guengerich FP \& Coon MJ (1980) Interactions of cytochrome P-450, NADPH-cytochrome P-450 reductase, phospholipid, and substrate in the reconstituted liver microsomal enzyme system. Fournal of Biological Chemistry 255 4112-4119.

Gilep AA, Estabrook RW \& Usanov SA (2003) Molecular cloning and heterologous expression in E. coli of cytochrome P45017 alpha. Comparison of structural and functional properties of substrate-specific cytochromes $\mathrm{P} 450$ from different species. Biochemistry (Moscow) 68 86-98.

Graham SE \& Peterson JA (1999) How Similar Are P450s and What Can Their Differences Teach Us? Archives of Biochemistry and Biophysics 369 24-29.

Guengerich FP (1983) Oxidation-reduction properties of rat liver cytochromes $\mathrm{P} 450$ and NADPH-cytochrome $\mathrm{P} 450$ reductase related to catalysis in reconstituted systems. Biochemistry 22 2811-2820.

Guengerich FP, Krauser JA \& Johnson WW (2004) Rate-limiting steps in oxidations catalyzed by rabbit cytochrome P450 1A2. Biochemistry 43 10775-10788.

Hosaka M, Oshima H \& Troen P (1980) Studies of the human testis. XIV. Properties of C17-C20 lyase. Acta Endocrinology 94 389-396.

Hunte C, Kannt A, Lancaster CRD \& Michel H (2000) Structures and mechanisms of complexes from respiratory chains. Frontiers Science Series 31 125-133.

Imai T, Globerman H, Gertner JM, Kagawa N \& Waterman MR (1993) Expression and purification of functional human 17a-hydroxylase/17,20-lyase (P450c17) in Escherichia coli. Use of this system for study of a novel form of combined 17a-hydroxylase/17,20-lyase deficiency. Fournal of Biological Chemistry 268 19681-19689.

Imaoka S, Imai Y, Shimada T \& Funae Y (1992) Role of phospholipids in reconstituted cytochrome P450 3A form and mechanism of their activation of catalytic activity. Biochemistry $316063-6069$.

Immoos CE, Chou J, Bayachou M, Blair E, Greaves J \& Farmer PJ (2004) Electrocatalytic reductions of nitrite, nitric oxide, and nitrous oxide by thermophilic cytochrome P450 CYP119 in film-modified electrodes and an analytical comparison of its catalytic activities with myoglobin. Foumal of the American Chemical Society 126 4934-4942.

Ivanov YD, Kanaeva IP, Gnedenko OV, Pozdnev VF, Shumyantseva VV, Samenkova NF, Kuznetsova GP, Tereza AM, Schmid RD \& Archakov AI (2001) Optical biosensor investigation of interactions of biomembrane and water-soluble cytochromes P450 and their redox partners with covalently immobilized phosphatidylethanolamine layers. Fournal of Molecular Recognition 14 185-196.

Iwuoha EI, Kane S, Ania CO, Smyth MR, de Montellano PRO \& Fuhr U (2000) Reactivities of organic phase biosensors 3: electrochemical study of cytochrome P450 cam immobilised in a methyltriethoxysilane sol-gel. Electroanalysis 12 980-986.

Jenkins CM \& Waterman MR (1998) NADPH-flavodoxin reductase and flavodoxin from Eschericia coli: characteristics as a soluble microsomal P450 reductase. Biochemistry 37 6106-6113.

Johnson DL, Thompson JL, Brinkmann S, Schuller KA \& Martin LL (2003) Electrochemical characterisation of purified Rhus vernicifera laccase - voltammetric evidence for a sequential 4-electron transfer. Biochemistry 10 10229-10237.

Johnson DL, Lewis BC, Elliott D, Miners JO \& Martin LL (2005) Purification and electrochemical characterisation of human cytochrome P450 2C9 (CYP2C9). Biochemical Pharmacology $691533-1541$.
Joseph S, Rusling JF, Lvov YM, Friedberg T \& Fuhr U (2003) An amperometric biosensor with human CYP3A4 as a novel drug screening tool. Biochemical Pharmacology 65 1817-1826.

Kazlauskaite J, Westlake ACG, Wong L-L \& Hill HAO (1996) Direct electrochemistry of cytochrome P450 cam. Fournal of the Chemical Society, Chemical Communications 2189-2190.

Kuwada M (1999) A two-step purification of cytocrome P450 from adult pig testis by pregnenolone affinity column chromatography. Biomedical Chromatography 13 344-349.

Kuwada M, Sugano S \& Maki J (2001) Purification of cytochromes $\mathrm{P} 450_{\text {scc }}$ and $\mathrm{P} 450_{17 \mathrm{a}}$ by steroid-binding affinity column chromatography. Fournal of Biochemical and Biophysical Methods 49 417-431.

Laviron E (1979) General expression of the linear potential sweep voltammogram in the case of diffusionless electrochemical system. Fournal of Electroanalytical Chemistry 101 19-28.

Lee-Robichaud P, Shyadehi AZ, Wright JN, Akhtar ME \& Akhtar M (1995a) Mechanistic kinship between hydroxylation and desaturation reactions: acyl-carbon bond cleavage promoted by pig and human CYP17 (P-450(17)alpha; 17 alpha-hydroxylase17,20-lyase). Biochemistry 34 14104-14113.

Lee-Robichaud P, Wright JN, Akhtar ME \& Akhtar M (1995b) Modulation of the activity of human 17 alpha-hydroxylase17,20-lyase (CYP17) by cytochrome b5: endocrinological and mechanistic implications. Biochemical foumal 308 901-908.

Lei C, Wollenberger U, Jung G \& Scheller FW (2000) Clay-bridged electron transfer between cytochrome $\mathrm{P} 450$ cam and electrode. Biochemical and Biophysical Research Communications 268 740-744.

Lewis DF \& Hlavica P (2000) Interactions between redox partners in various cytochrome P450 systems: functional and structural aspects. Biochimica and Biophysica Acta $1460353-374$.

Li H (2001) Cytochrome P450. In Handbook of Metalloproteins, pp 267-282. Eds A Messerschmidt, R Huber, K Wieghardt \& T Poulos. Chichester: John Wiley \& Sons.

Light DR \& Orme-Johnson NR (1981) Beef adrenal cortical cytochrome P450 which catalyzes the conversion of cholesterol to pregnenolone. Fournal of Biological Chemistry 256 343-350.

Lvov YM, Lu Z, Schenkman JB, Zu X \& Rusling JF (1998) Direct electrochemistry of myoglobin and cytochrome P450 cam in alternate layer-by-layer films with DNA and other polyions. Journal of the American Chemical Society 120 4073-4080.

Mao J, Hauser K \& Gunner MR (2003) How cytochromes with different folds control heme redox potentials. Biochemistry 42 9829-9840.

Miwa GT \& Lu AYH (1981) Studies on the stimulation of cytochrome P-450-dependent monooxygenase activity by dilauroylphosphatidylcholine. Archives of Biochemistry and Biophysics 211454458.

Mouro C, Bondon A, Jung C, Hui Bon Hoa G, De Certaines JD, Spencer RGS \& Simonneaux G (1999) Proton nuclear magnetic resonance study of the binary complex of cytochrome $\mathrm{P} 450$ cam and putidaredoxin: interaction and electron transfer rate analysis. FEBS Letters 455 302-306.

Munge B, Estavillo C, Schenkman JB \& Rusling JF (2003) Optimization of electrochemical and peroxide-driven oxidation of styrene with ultrathin polyion films containing cytochrome P450 cam and myoglobin. Chembiochem 4 82-89.

Nicolini C, Erokhin V, Ghisellini P, Paternolli C, Kumar Ram M \& Sivozhelezov V (2001) P450 scc engineering and nanostructuring for cholesterol sensing. Langmuir 17 3719-3726.

Omata Y, Aibara K \& Ueno Y (1987) Conformation between the substrate-binding site and heme of cytochrome P-450 studied by excitation energy transfer. Biochemistry and Biophysics 912 115-123.

Omura T (1999) Forty years of cytochrome P450. Biochemical and Biophysical Research Communications 266 690-698.

Peterson JA \& Graham SE (1998) A close family resemblance: the importance of structure in understanding cytochromes P450. Structure 6 1079-1085. 
Reid LS, Mauk MR \& Mauk AG (1984) Role of heme propionate groups in cytochrome $b_{5}$ electron transfer. Fournal of the American Chemical Society 106 2182-2185.

Reipa V, Mayhew MP, Holden MJ \& Vilker VJ (2002) Redox control of the P450 cam catalytic cycle: effects of Y96F active site mutation and binding of a non-natural substrate. Fournal of the Chemical Society, Chemical Communications 318-319.

Ruckpaul K, Rein H, Blanck J, Ristau O \& Coon MJ (1982) Molecular mechanisms of interactions between phospholipids and liver microsomal cytochrome P450 LM2. Acta biologica et medica Germanica 41 193-203.

Rusling JF (1998) Enzyme bioelectrochemistry in cast biomembranelike films. Accounts of Chemical Research 31 363-369.

Scott EE, White MA, He YA, Johnson EF, Stout CD \& Halpert JR (2004) Structure of mammalian cytochrome P450 2B4 complexed with 4-(4-chlorophenyl)imidazole at 1.9-A resolution: insight into the range of $\mathrm{P} 450$ conformations and the coordination of redox partner binding. Fournal of Biological Chemistry $27927294-27301$.

Sherbet DP, Tiosano D, Kwist KM, Hochberg Z \& Auchus RJ (2003) CYP17 Mutation E305 G Causes Isolated 17,20-Lyase Deficiency by Selectively Altering Substrate Binding. Fournal of Biological Chemistry 278 48563-48569.

Sligar SG (1976) Coupling of spin, substrate, and redox equilibria in cytochrome P450. Biochemistry 15 5399-5406.

Sligar SG \& Gunsalas IC (1976) A thermodynamic model of regulation: modulation of redox equilibria in camphor monoxygenase. PNAS 73 1078-1082.

Stevens TJ \& Arkin IT (1999) Are membrane proteins 'inside out' proteins? Proteins 36 135-143.
Swinney DC \& Mak AY (1994) Androgen formation by cytochrome P450 CYP17. Solvent isotope effect and pL studies suggest a role for protons in the regulation of oxene versus peroxide chemistry. Biochemistry 33 2185-2190.

Voznesensky AI \& Schenkman JB (1994) Quantitative analyses of electrostatic interactions between NADPH-cytochrome P450 reductase and cytochrome P450 enzymes. Fournal of Biological Chemistry 269 15724-15731.

Williams PA, Cosme J, Ward A, Angove HC, Matak Vinkovic D \& Jhoti H (2003) Crystal structure of human cytochrome P450 2C9 with bound warfarin. Nature $424464-468$.

Williams PA, Cosme J, Vinkovic DM, Ward A, Angove HC, Day PJ, Vonrhein C, Tickle IJ \& Jhoti H (2004) Crystal structures of human cytochrome P450 3A4 bound to metyrapone and progesterone. Science 305 683-686.

Yamazaki H, Johnson WH, Ueng Y-F, Shimada T \& Guengerich FP (1996) Lack of electron transfer from cytochrome $b_{5}$ in stimulation of catalytic activities of cytochrome P4503A4. Fournal of Biological Chemistry 271 27438-27444.

Yun C-H, Ahn T \& Guengerich FP (1998) Conformational change and activation of cytochrome P450 2B1 induced by salt and phospholipid. Archives of Biochemistry and Biophysics 356 229-238.

Zhang Z, Nassar A-EF, Lu Z, Schenkman J \& Rusling JF (1997) Direct electron injection from electrodes to cytochrome P450 cam in biomembrane-like films. Foumal of the Chemical Society, Faraday Transactions 93 1769-1774.

Received 17 October 2005

Accepted 30 November 2005

Made available online as an Accepted Preprint 7 December 2005 